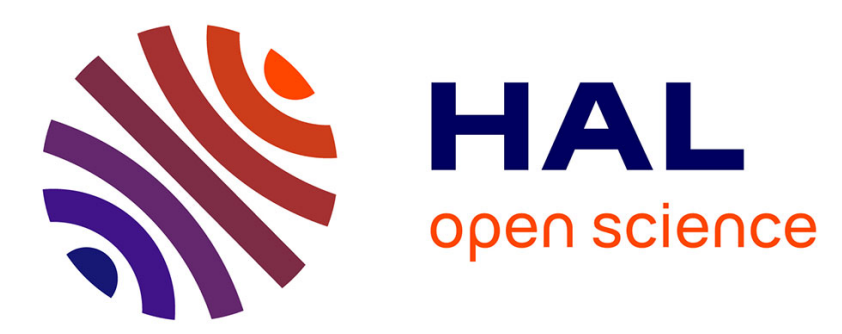

\title{
Experimental Bifurcation Diagram and Terminal Voltage Change of an External-cavity Semiconductor Laser
}

\author{
Byungchil Kim, Nianqiang Li, A. A Sahai, A. Locquet, D. S Citrin
}

\section{To cite this version:}

Byungchil Kim, Nianqiang Li, A. A Sahai, A. Locquet, D. S Citrin. Experimental Bifurcation Diagram and Terminal Voltage Change of an External-cavity Semiconductor Laser. CLEO: Applications and Technology, 2014, San Jose, United States. pp.JW2A.105, 10.1364/CLEO_AT.2014.JW2A.105 . hal03085265

\section{HAL Id: hal-03085265 https://hal.science/hal-03085265}

Submitted on 21 Dec 2020

HAL is a multi-disciplinary open access archive for the deposit and dissemination of scientific research documents, whether they are published or not. The documents may come from teaching and research institutions in France or abroad, or from public or private research centers.
L'archive ouverte pluridisciplinaire HAL, est destinée au dépôt et à la diffusion de documents scientifiques de niveau recherche, publiés ou non, émanant des établissements d'enseignement et de recherche français ou étrangers, des laboratoires publics ou privés. 


\title{
Experimental Bifurcation Diagram and Terminal Voltage Change of an External-cavity Semiconductor Laser
}

\author{
Byungchil Kim, ${ }^{1,2, *}$ Nianqiang Li, ${ }^{3,1}$ A. A. Sahai, ${ }^{1,2}$ A. Locquet, ${ }^{2,1}$ and D. S. Citrin ${ }^{1,2}$ \\ ${ }^{1}$ Georgia Institute of Technology, School of Electrical and Computer Engineering, Atlanta, Georgia 30332-0250 USA \\ ${ }^{2}$ UMI 2958 Georgia Tech-CNRS, Georgia Tech Lorraine, 2 Rue Marconi F-57070, Metz, France \\ ${ }^{3}$ Centers for Information Photonics and Communications, Southwest Jiaotong University, Chengdu, 610031 China \\ *gtg403z@mail.gatech.edu
}

\begin{abstract}
We present for the first time experimental bifurcation diagrams of an externalcavity semiconductor laser using the photodetected optical intensity and the laser diode terminal voltage and interpret them on the basis of the Lang and Kobayashi model.
\end{abstract}

(C) 2014 Optical Society of America

OCIS codes: (140.1540) Chaos Lasers; (140.2020) Semiconductor lasers.

\section{Introduction}

The dynamics of external-cavity semiconductor lasers (ECSLs) are known to be complex and difficult to control; in view of the rich dynamical behavior, which has applications in secure communications, high-speed random number generation, and optical reservoir computing, as well as the technological importance of these devices, the dynamics have been widely investigated. The bifurcation diagram (BD) provides an easily apprehended depiction of transitions between dynamical regimes as a parameter is changed. Nonetheless, there is an almost total lack of experimental BDs available for ECSLs because there are several experimental hurdles we have overcome that necessarily need to be resolved to obtain a general picture. Especially for ECSLs, BDs require a precise control of the feedback strength and accurate and stable thermal and mechanical controls, which are difficult to achieve. There is a need for such measurements as they provide a way to test the reliability of models for the laser dynamics, such as the Lang and Kobayashi (LK) model [1].

We report experimental BDs of an ECSL that the closest operation conditions were in [2], where Hohl and Gavrielides focused on the case of an ECSL biased just above threshold and subjected to feedback from a distant reflector (long-cavity case) and observed a cascade of bifurcations between ECMs. Importantly, results map out, for the first time to our knowledge, detailed bifurcation diagrams of ECSLs as function of a feedback strength for various external cavity length $(L)$ and current $(I)$, thus covering a significant portion of parameter space. Also, we report for the first time that the laser diode terminal voltage can be used to determine the dynamical regime of the laser. We have grounded our discussion in the extensive theoretical studies based on the LK equations and observed a cascade of BDs in accordance with our experimental results [3].

\section{Bifurcation-cascade diagram}

The semiconductor laser used in our experiments is an intrinsically single-longitudinal mode InGaAsP DFB laser that oscillates at wavelength $1550 \mathrm{~nm}$ with maximum power of $15 \mathrm{~mW}$. The free-running threshold current $\left(I_{\text {th }}\right)$ is 9.27 $\mathrm{mA}$. A real-time oscilloscope with $12 \mathrm{GHz}$ bandwidth is used to capture the time series of the optical intensity. We show the experimentally observed bifurcation cascade for $I=11.24 \mathrm{~mA}, L=30 \mathrm{~cm}$ [Fig. 1 (a)], $I=14.69 \mathrm{~mA}, L=30$ $\mathrm{cm}$ [Fig. 1(b)] and $I=11.24 \mathrm{~mA}, L=15 \mathrm{~cm}$ [Fig. 1(c)]. The experimental BD is obtained by taking the local extrema of the intensity time series from a high-speed oscilloscope as a function of $\eta$. A bifurcation cascade between apparently stable and unstable regions is observed. The successive stable regions are identified to correspond to the ECL settling on the maximum-gain modes (MGMs) appearing successively as the feedback is increased. Because of the low current chosen, the photodetected optical intensity is weak and does not always stand out of system noise.

We observe three marked phenomena with increasing $I$ [Fig.1 (a) and (b)]. The first is that alternating stable and unstable regions are still observed, but no longer a systematic cascade involving the successive MGMs. The second is 

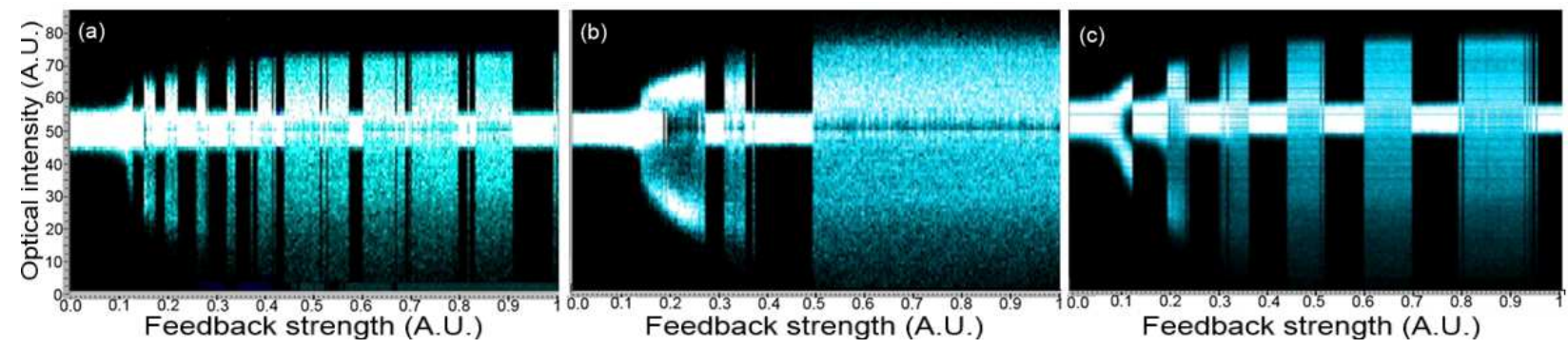

Fig. 1. Experimentally observed bifurcation cascade for (a) $\mathrm{I}=11.24 \mathrm{~mA}, \mathrm{~L}=30 \mathrm{~cm}$, (b) $\mathrm{I}=14.69$ $\mathrm{mA}, \mathrm{L}=30 \mathrm{~cm}$, and $(\mathrm{c}) \mathrm{I}=11.24 \mathrm{~mA}, \mathrm{~L}=15 \mathrm{~cm}$.

that the cascade exhibits interrupted chaotic behavior above a feedback level that decreases with increasing $I$. Indeed, we have observed consistently the presence of alternating "stable" and "unstable" regions for all values of the current between $I_{\text {th }}$ and $1.5 I_{\text {th }}$. The third is that for larger $I$, longer (though fewer) regions of stable CW emission exist compared to low $I$. Also, the dependence of the BD on $L$ is explored in Fig. 1(a) and (c). At a short $L$, we again observe a cascade of bifurcations, but with significantly longer stable regions during which the laser output power dwells on a single ECM before moving into the subsequent unstable regime, itself followed by the next ECM.
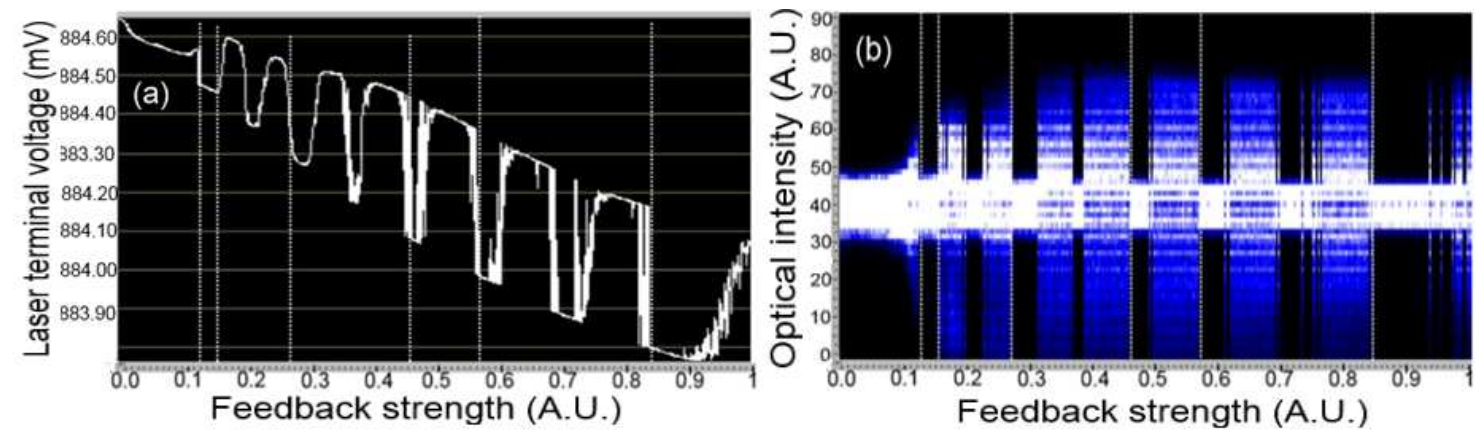

Fig. 2. Experimental laser terminal voltage and corresponding bifurcation diagram.

Figure 2 shows laser terminal voltage and corresponding BD. The laser diode is driven using a constant current power supply. The diode package is maintained at a constant temperature using an externally controlled thermoelectric cooler. Using experimental data it is shown that increasing the feedback level at a fixed external cavity length, the laser diode terminal voltage displays jumps that are consistent with the cascade of bifurcations.

In order to validate our interpretation of the experimental results, we have carried out theoretical calculations based on the well known LK model. Despite its simplifications, this model successfully explains qualitatively our experimental results. At low current, the unstable regions correspond to the low frequency fluctuation (LFF) regime, which involves a drift toward the MGM. At larger current, the unstable regions typically correspond to fully-developed CC, with no drift toward the MGM, explaining the reduced number of stable regions observed. Additionally, the increase in the distance between ECMs for smaller cavities explains the observed reduction in the number of stable regions.

\section{References}

1. R. Lang and K. Kobayashi, "External optical feedback effects on semiconductor injection-laser properties," IEEE J. Quantum Electron. 16, 347-355 (1980).

2. A. Hohl and A. Gavrielides, "Bifurcation cascade in a semiconductor laser subject to optical feedback," Phys. Rev. Lett. 82, 1148-1151 (1999).

3. B. Kim, N. Li, A. Locquet, and D.S. Citrin,"Experimental bifurcation-cascade diagram of an external-cavity semiconductor laser," accepted for publication in Opt. Express (2014). 